ARCHIVO ESPAÑOL DE ARTE, XCIII, 370

ABRIL-JUNIO 2020, pp. 161-170

ISSN: 0004-0428, eISSN: 1988-8511

https://doi.org/10.3989/aearte.2020.12

\title{
UN SAN ANDRÉS DE JUAN DE JÁUREGUI ENTRE LA DOTACIÓN ARTÍSTICA DEL CONVENTO MADRE DE DIOS DE BAENA
}

\author{
Francisco Manuel Carmona Carmona ${ }^{1}$ \\ Universidad de Córdoba
}

\begin{abstract}
En esta contribución pretendemos un doble propósito: contextualizar el proceso de dotación artística de la capilla mayor del convento Madre de Dios por parte de la V duquesa de Sessa; y, dar a conocer un lienzo que la documentación señala es obra de Juan de Jáuregui y Aguilar (Sevilla, 1583 — Madrid, 1641).

Palabras clave: Doña Juana Fernández de Córdoba Cardona y Aragón; pintura italiana del siglo XVI; pintura española del siglo XVII; testamento; inventario y tasación de obras; atribución.
\end{abstract}

\section{A SAINT ANDREW'S PORTRAIT BY JUAN DE JÁUREGUI AS PART OF THE ARTISTIC ENDOWMENT OF THE MADRE DE DIOS CONVENT IN BAENA}

\begin{abstract}
With this contribution we try a double objective. First, contextualize the compilation process of the artistic work that is shown in the main chapel of the Madre de Dios convent in Baena by the Fifth Duchess of Sessa. Second, to present a canvas that indicates the documentation is the work of Juan de Jáuregui Aguilar (1583-1641).

Key words: Mrs. Juana Fernandez de Cordoba Cardona Aragon; Italian painting of the sixteenth century; Spanish painting of the seventeenth century; Will; Index and economic appreciation of artistic works; Attribution of authorship.
\end{abstract}

Cómo citar este artículo / Citation: Carmona Carmona, Francisco Manuel (2020): "Un San Andrés de Juan de Jáuregui entre la dotación artística del convento Madre de Dios de Baena". En: Archivo Español de Arte, vol. 93, núm. 370, Madrid, pp. 161-170. https://doi.org/10.3989/aearte.2020.12.

El papel ejercido por los conventos femeninos en la conservación y defensa del patrimonio artístico y documental es más que evidente. Fundamentalmente porque estas comunidades han actuado tanto de baluartes en el mantenimiento de sus arquitecturas monumentales como de contenedores inmejorables en el atesoramiento del patrimonio artístico de naturaleza mueble. En el fenómeno conventual cordobés, y concretamente de la Segunda Orden de Santo Domingo o de Dominicas, hemos detectado que en el proceso de reunión de piezas artísticas han tenido un intenso protagonismo las religiosas que pueblan estos cenobios, así como también sus familias directas o parientes. No obstante, las iglesias conventuales y, en concreto sus capillas mayores, fueron concebidas como herramienta fundamental de las clases sociales privilegiadas, desde donde se materializó buena parte de su representación política y social, por lo que eran menester grandes esfuerzos en materia artística y magnificente.

En el convento Madre de Dios de Baena la dotación ornamental de su capilla mayor fue realizada gracias a los auspicios de los V duques de Sessa y III de Baena a finales del siglo XVI,

${ }^{1}$ aa2carcf@uco.es/ ORCID iD: http://orcid.org/0000-0003-1118-3271 
quienes prefirieron considerarla como su panteón en la villa principal de sus estados. El duque don Antonio Fernández de Córdoba fue embajador ante la Santa Sede entre 1590 y 1604, un periodo en el que comenzó a promover junto a su esposa la compra del patronato de la capilla mayor de la iglesia conventual ${ }^{2}$. Desde muy pronto empezaron a enviar estructuras y obras de arte para su adecuación, como el retablo de mármol blanco y travertino, el manifestador de bronce con taracea de jaspes y lapislázuli, y algunas piezas orfebres conteniendo reliquias. Así, en un contexto de servicio a la monarquía hispánica, los duques de Sessa también participaron de la costumbre de adquirir obras de arte para significar su residencia romana; unas piezas que concluido su mandato se embarcaban con destino a España ${ }^{3}$. Por esta vía se comenzó a proveer al convento de numerosas obras artísticas que fueron compradas durante la legación vaticana con la clara intención de favorecer el establecimiento del patronato privativo de la capilla mayor.

El duque don Antonio pidió la capilla y entierro de esta casa para que lo fuese propia y perpetua para sí con intento de adornarla, autorizarla y engrandecerla como lo comenzó a hacer desde Roma enviando el edificio y retablo que está puesto de piedra en el altar con el rico y lucido sagrario de bronce y la imagen de Nuestra Señora que le donó Clemente VIII puesta en el tabernáculo [...] Murió este grande príncipe, y quedó a cargo de la excelentísima señora doña Juana de Córdoba y Aragón, su mujer, el continuar y perfeccionar lo comenzado y dispuesto por el testamento del dicho señor [...] Envió la espina de Cristo preciosísima que está en el sagrario, tiene otras muchas reliquias [en glosa: Dio el santo sudario la más grande de las reliquias, el título de la cruz de Cristo, la medalla de indulgencias y otras muchas reliquias], ornamentos y cosas preciosas y de valor para enriquecer su capilla y casa ${ }^{4}$.

Consiguió el patronato perpetuo de la capilla mayor conventual la duquesa doña Juana en el verano de 1634, según nos informa la escritura de obligación otorgada con la priora y monjas del convento, previo plácet del maestro provincial de Andalucía:

Se ha concertado el patronazgo privativo e insolidum de la capilla mayor de la iglesia del monasterio de Madre de Dios de la villa de Baena, por lo cual y para los reparos de la dicha capilla mayor la señora duquesa había de dar para después de los días de su vida cuatro mil ducados de principal de un censo [...] Tres mil de los cuales para el monasterio en razón del patronazgo y los otros mil ducados para que con los réditos se repare dicha capilla y se compren ornamentos para el culto divino 5 .

Por tanto, hasta el fallecimiento de la duquesa en enero de 1638 no se produce la materialización efectiva del patronazgo de la capilla mayor conventual, dado que así nos lo señalan tanto los archivos, los entierros del matrimonio ducal y de su hijo el Príncipe de Maratea, y la dotación ornamental de la que hoy sigue haciendo gala este cenobio ${ }^{6}$ [fig. 1].

\section{... todos los ornamentos y plata de mi capilla se llevarán a Madre de Dios}

A la duquesa de Sessa y Baena, doña Juana de Córdoba y Aragón, la señala la historiografía como una rara avis entre las mujeres del siglo XVII español. Su vasta cultura literaria y artística

2 "a 2 de iuglio, 195 moneta de mandato de S.E. pagati al Sr Gonçalo de Navarrete, disse per spedittione della bulla del Patronasgo de Baena". Libro de despachos, Roma, 16/01/1593. Archivo Histórico de la Nobleza, Toledo (AHNOB). Baena, C. 12, D. 5, f. 36r.

${ }_{3}$ Monterroso / García, 2010: 8.

${ }^{4}$ Libro de la Hacienda. Archivo Conventual Madre de Dios de Baena (ACMDB), C. 1, f. 271r.

5 Escritura de obligación, Madrid, 08/07/1634. ACMDB, C. 2, ff. 490r-513r.

${ }^{6}$ Libro de la Hacienda. ACMDB, C. 1, f. 271r. Transcribe y desarrolla las epigrafías Valverde, 1903: 328-330. Los instrumentos empleados para la legitimación del poder y prestigio de la casa de Cabra-Sessa-Baena en la principal villa de sus estados se exponen en Carmona, 2017a. Carmona, 2017b: 90-96. Carmona, 2019a. 


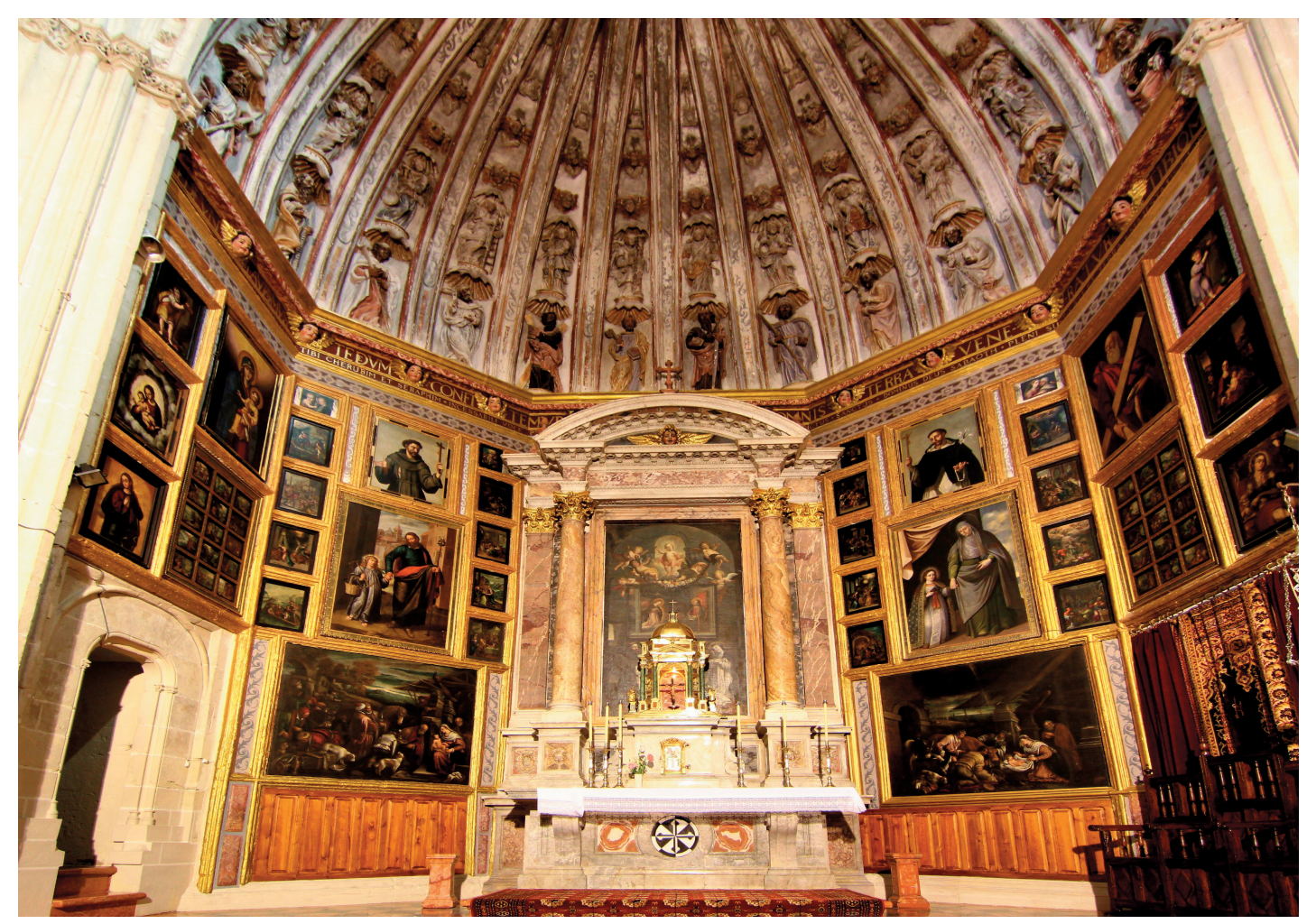

Fig. 1. Baena, iglesia conventual de Madre de Dios, vista general del retablo pictórico de la capilla mayor. Foto del autor.

se vio sin duda enriquecida gracias a su estancia en Roma, acompañando a su esposo en la legación diplomática en el Vaticano. Pruebas de ello las ofrecen, de un lado su testamento, con una serie de mandas y donaciones de muebles y obras de arte donde se deja expresa constancia su origen italiano, del que el convento de dominicas baenense sale notablemente beneficiado:

A la señora doña Beatriz de Cardona $^{7}$ un cuadro grande de Florencia y un escritorio de ébano y marfil [...] Todos los demás cuadros grandes y pequeños, de cualquier manera que sean, y todas las reliquias, y la espina de Cristo y el Eccehomo de plata dorado, y todos los ornamentos y plata de mi capilla se llevará a Madre de Dios de Baena, para adorno de la capilla del duque mi señor y mía ${ }^{8}$.

De otro lado, si atendemos a los inventarios y tasaciones de sus bienes, destacan en su librería volúmenes de edición romana y una importante colección pictórica de indudable origen italiano. De ello nos da cuenta Barrio Moya ${ }^{9}$, lo que permite comprobar cómo buena parte de las piezas artísticas del oratorio de la duquesa, tanto de orfebrería como pictóricas ${ }^{10}$, fueron a parar a Madre de Dios de Baena.

\footnotetext{
7 Doña Beatriz de Cristo Cardona, era hija natural del III duque de Soma, sobrina de la testadora, fue priora entre 1601 y 1609 y es considerada pieza fundamental en el logro de establecer el patronato de los duques de Sessa y Baena. Carmona, 2019a: 204.

8 Testamento de doña Juana Fernández de Córdoba Cardona Aragón, Madrid, 27/03/1634. AHNOB. Baena, C. 127, D. 208, f. $12 \mathrm{v}$.

9 Barrio, 1984.

${ }^{10}$ Hemos identificado distintas piezas orfebres referidas en el inventario de la duquesa de Sessa "con su escudo de armas" de las que se relacionan en Orti/Bernier/Nieto/Lara, 1981: 192-193; mientras que determinadas obras pictóricas se han dado a conocer en Carmona, $2019 \mathrm{~b}$.
} 


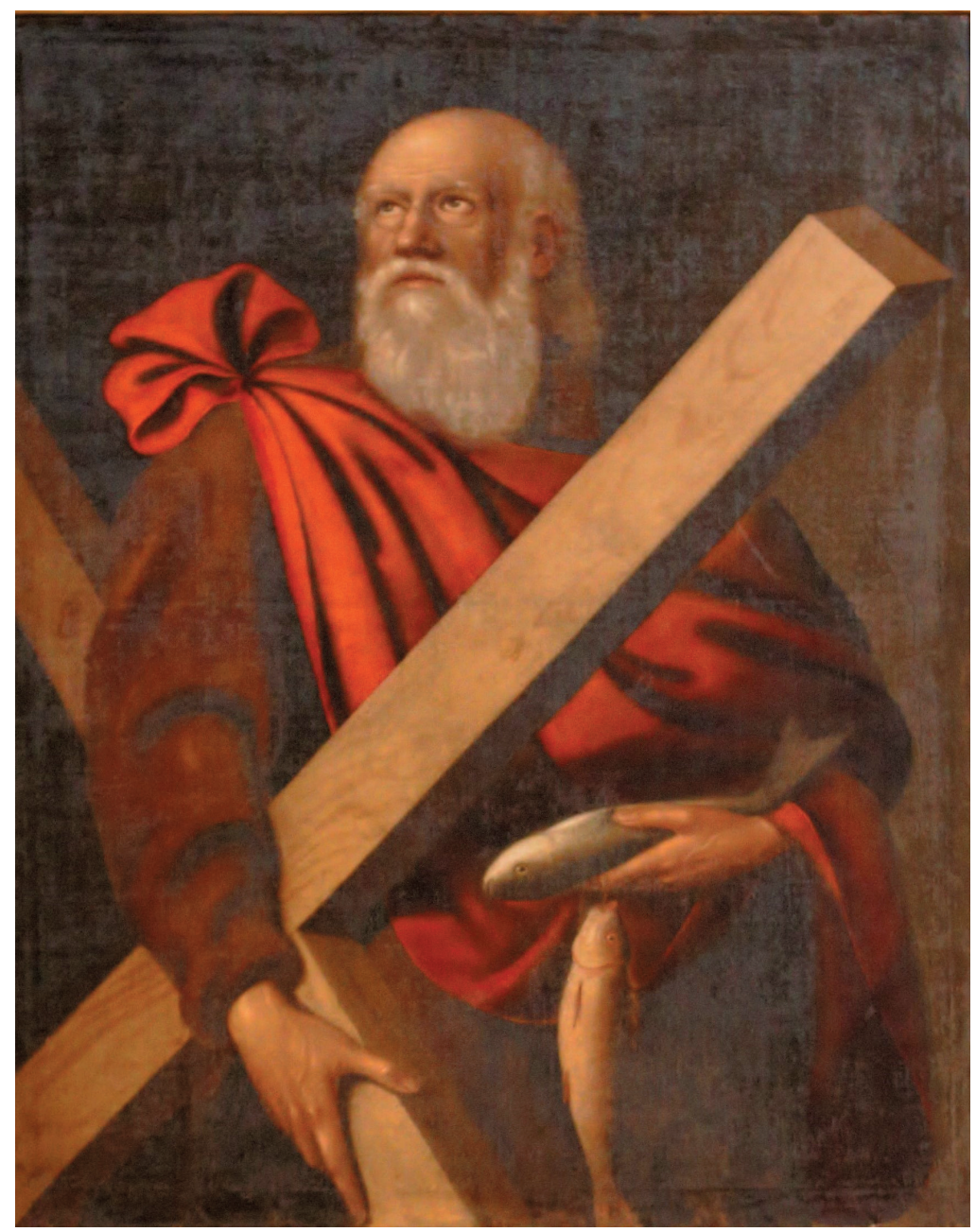

Fig. 2. Juan de Jáuregui y Aguilar, Baena, iglesia conventual de Madre de Dios, capilla mayor, Apóstol San Andrés, ca. 1620-1630. Foto del autor.

La colección pictórica de la duquesa de Sessa se correspondía bien con su librería, por cuanto que la temática era exclusivamente religiosa, con algunos retratos de santos. Varios de sus cuadros procedían de Italia, como los dos de Pulzone y algunos más. Con respecto a los autores de las pinturas, [el pintor y tasador] Bartolomé Román sólo menciona un Ecce Homo y una Virgen de la Piedad de Scipión Pulzone [tasados en 300 reales cada uno], y un San Andrés de don Juan de Jáuregui [tasado en 200 reales] ${ }^{11}$.

Sobre estas tres obras pertenecientes a la duquesa de Sessa ya se había referido Barrio Moya un año antes ${ }^{12}$, destacando la fortuna de haber localizado un inventario y tasación de piezas artísticas donde se alude explícitamente al nombre de su autoría. En concreto, el tasador se refiere claramente a Scipione Pulzone (1544-1598), al nombrarlo como Cipion Gaetano adscribiéndole dos obras, demostrando así su "conocimiento grande sobre el artista italiano", y otra obra más a Juan de Jáuregui. Solo resta demostrar que los últimos deseos de doña Juana se llevaron a cabo cuando se trasladaron a Baena todos los objetos muebles de valor de la capilla privada madrileña. Y así fue, pues comprobamos que buena parte de las piezas de su inventario post mortem tuvo como destino Madre de Dios, como más adelante veremos.

\footnotetext{
11 Barrio, 1984: 49

12 Barrio, 1983.
} 


\section{El San Andrés de don Juan de Jáuregui}

El lienzo que representa al apóstol San Andrés $(\approx 100 \times 65 \mathrm{~cm})$ lo señala la documentación como obra indubitable del poeta-pintor Juan de Jáuregui y formando parte del legado testamentario de la duquesa de Sessa y Baena [fig. 2]. Tanto las declaraciones de la última voluntad de doña Juana como los inventarios y tasaciones de bienes, nos indican la calidad de obras artísticas que serían llevadas a Madre de Dios para formar parte del original retablo pictórico de su capillapanteón. De entre ellas cabe destacar la pintura del apóstol, pues nos señala implícitamente la gran estima que Juan de Jáuregui contaba como pintor en el Madrid de 1638, al valorarse su obra con la nada despreciable cifra de 200 reales, en comparación con el resto de tasaciones.

La fortuna crítica de Juan de Jáuregui ha ido a la par señalada por su actividad literaria y por atribuírsele presuntamente la autoría del retrato de Miguel de Cervantes que preside el salón de actos de la Real Academia Española. Su formación literaria y artística se forjó en Sevilla, estando fuertemente influenciada por destacadas figuras de su tiempo. Hubo de realizar un viaje de formación a Roma durante la primera década del siglo XVII, donde tuvo oportunidad de traducir del italiano Aminta, obra de Torcuato de Tasso, que le granjeó gran predicamento. De regreso en su Sevilla natal en 1609, se le documenta que empezó a fraguar una destacada carrera literaria en la que sin duda sirvió como detonante su Antídoto contra la pestilente poesía de las 'Soledades', de 1614, un verdadero vejamen a la obra de Luis de Góngora que publicó un año antes, lo que provocó estallara entre ambos autores una guerra dialéctica que se prolongaría durante décadas. En 1619 Jáuregui pasó a residir en Madrid, donde ocupó importantes cargos gracias al más que presumible adminículo del Conde Duque de Olivares. Paralelamente a los cargos de censor oficial y caballerizo de la reina, tuvo oportunidad de diseñar los retratos del jurisconsulto e historiador Alfonso de Carranza y del humanista Lorenzo Ramírez de Prado, para que trasladados al grabado ilustraran las primeras páginas de sus obras, como era habitual entre los autores de la época ${ }^{13}$.

No cabe duda que la faceta de pintor de Jáuregui es la más desconocida, ignorándose hasta ahora obras de su autoría ${ }^{14}$, salvo la referencia indirecta de la trasmutación grabada de los referidos retratos de Carranza y Ramírez, y la narración que Cervantes hizo en sus Novelas ejemplares (1613) sobre esta actividad pictórica del poeta sevillano:

Quisiera yo, si fuera posible, lector amantísimo, escusarme de escribir este prólogo, porque no me fue tan bien con el que puse en mi Don Quijote, que quedase con gana de segundar con éste. Desto tiene la culpa algún amigo, de los muchos que en el discurso de mi vida he granjeado, antes con mi condición que con mi ingenio; el cual amigo bien pudiera, como es uso y costumbre, grabarme y esculpirme en la primera hoja deste libro, pues le diera mi retrato el famoso don Juan de Jáuregui, y con esto quedara mi ambición satisfecha, y el deseo de algunos que querrían saber qué rostro y talle tiene quien se atreve a salir con tantas invenciones en la plaza del mundo, a los ojos de las gentes, poniendo debajo del retrato.

Pese a que la cita no indica a las claras que Cervantes hubiese sido realmente retratado por Jáuregui, pues el pretérito le diera mi retrato puede contener una crítica, no falta de chanza, a la costumbre de sus contemporáneos literatos de encabezar sus obras con su efigie, lo cierto es que la historiografía, desde comienzos del siglo XX, le viene señalando autor del presunto retrato cervantino de la Academia. A ello anima que en el cuadro se inscribe: "Don Miguel de Cervantes Saavedra / Iuan de Iauregui Pinxit, año 1600". Pese a la contundencia de la inscripción y que en

13 Diccionario Biográfico Español: <http://dbe.rah.es/biografias/13255/juan-de-jauregui-y-aguilar> [Consulta: 21/05/2019].

14 "He aquí un excelente retrato de fines del siglo XVI; no sabemos de quién es; tiene que ser de un buen pintor. Buen pintor lo era Jáuregui, si hemos de creer los elogios de los escritores antiguos, ya que no conocemos obras suyas. Este pudiera ser un Jáuregui”. Defensa del marqués de Casa Torres de la autoría de Jáuregui del presunto retrato cervantino de la RAE, según señala Lucía, 2016: 33-34. La cursiva es nuestra. 
ese año Cervantes continuaba avecindado en Sevilla, no ha sido óbice para que haya habido tantos acérrimos defensores de la causa jaureguista ${ }^{15}$ como categóricos detractores de que la efigie corresponda al autor del Quijote ${ }^{16}$, basando estos últimos sus fundamentos en evidenciar más una oportunidad histórica y de enaltecimiento patriótico que rigor en los juicios de atribución ${ }^{17}$. Por tanto, una buena ocasión esta para incluir en el catálogo creador de este poeta la única obra documentada - hasta el momento- de su ingenio pictórico.

El San Andrés de Madre de Dios debió ser pintado en Madrid en un contexto de búsqueda de mecenazgo nobiliario a imagen de sus contemporáneos literatos, presumiblemente en los primeros años de su estancia en la corte y algo antes de 1634, año en el que se realiza el testamento de la duquesa doña Juana, donde ya menciona su devoción por el apóstol, a quien toma como particular abogado e intercesor en el trance postrero de su vida ${ }^{18}$.

De las dotes de pintor de Jáuregui hemos de señalar que no son de un gran nivel técnico. Su San Andrés de Baena se muestra sobrio, apenas expresivo, idealizando la santidad de este miembro del colegio apostólico y sin arriesgar a considerar ningún aspecto psicológico más allá de una actitud contemplativa.

La composición la resuelve representando al santo aislado, sobre un fondo neutro, muy saturado de color en su lado superior izquierdo y degradando a tostado en el inferior derecho. La figura aparece de más de medio cuerpo y con el rostro de tres cuartos, girado hacia la izquierda y elevando la mirada. El modelo luce una amplia calva y abundante barba blanca, sujeta entre su cuerpo y la mano derecha la cruz en diagonal de sección cuadrada perfectamente dibujada y trabajada en el cromatismo de sus vetas. Viste túnica marrón y cubre gran parte de su cuerpo con un manto rojo que sujeta sobre su hombro derecho con un artificioso nudo. El protagonismo dado a la cruz y al encuadre de la figura recuerdan a sendas composiciones de este mismo apóstol surgidas del talento de El Greco y que pertenecen a su museo toledano y a la Catedral Primada.

Iconográficamente, como es frecuente, lo provee de los atributos que señalan la singularidad del personaje y arquetipo de su identidad: los peces que porta con su mano izquierda, aludiendo a su origen humilde como pescador en el mar de Galilea, y la más que evidente y bien compuesta cruz en forma de aspa, por ser el instrumento de su martirio.

Sobre el estado de conservación de esta pieza es obligado decir que el paso del tiempo, la calidad del lienzo y la deficiente preparación del mismo le han pasado una alta factura, amén de los avatares atravesados para su salvaguarda durante la Guerra Civil Española y bastantes años de la postguerra, en los que incluso se llegó a emparedar junto a otras valiosas obras artísticas para su defensa del expolio. Sin duda, el desconocimiento de su autoría, la escasez de brío en la composición y la gama cromática empleada no han ayudado a ponderar suficientemente esta obra. Algo que esperamos se reconduzca a partir de ahora.

\section{Todos los demás cuadros, grandes y pequeños, se llevarán a Madre de Dios...}

Del resto de la dotación ornamental de la capilla ducal venimos a confirmar que buena parte de las obras relacionadas en el testamento exhumado por Barrio Moya hoy se encuentran o han pertenecido a este convento de Baena. Tanto el Ecce Homo como la Virgen de la Piedad del

15 Especial interés en la defensa de autenticidad tuvieron el profesor José Albiol y el cervantista Francisco Rodríguez Marín, el director de la RAE Alejandro Pidal y Mon y el periodista y escritor Mariano de Cavia. Lucía, $2016: 31$.

16 Entre otros, el académico de la Historia Juan Pérez de Guzmán, los hispanistas Raymond Foulché-Delbosc y James Fitzmaurice-Kelly, o el escritor y periodista Ramón León Maínez. Lucía, 2016: 31.

17 Lucía, 2016: 30-34. No obstante, como dejó probado Lafuente Ferrari en 1948, el presunto retrato de Cervantes se trata de una burda falsificación, pese a que sigue presidiendo el dosel del salón de actos de la Real Academia Española junto al regio retrato de Felipe V, animando a esta pretenciosa doble falsedad de autoría e identidad.

18 Testamento de doña Juana Fernández de Córdoba Cardona Aragón. Madrid, 27/03/1634. AHNOB. Baena, C. 127 , D. 208 , f. $6 \mathrm{v}$. 


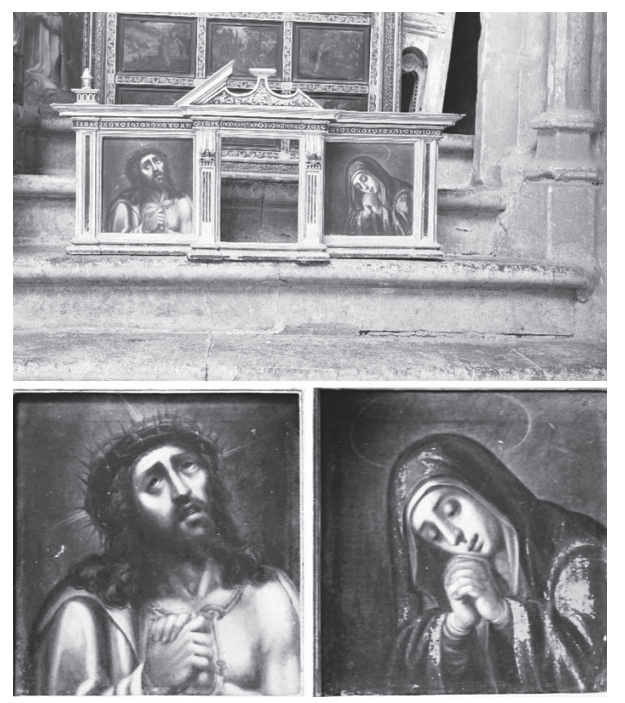

Fig. 3. Baena, iglesia conventual de Madre de Dios, retablo interior del altar de San Jacinto o de las reliquias y detalle del Ecce Homo y Virgen de la Piedad de Scipione Pulzone. Foto: Archivo Diputación de Córdoba. Catálogo Histórico Artístico Provincial: A364-239.
Gaetano formaron parte del legado testamentario realizado por la duquesa a partir de 1638 , unas obras que hoy permanecen en paradero desconocido pero que una fotografía histórica certifica de su existencia en Madre de Dios [fig. 3]. Lo cierto es que las obras del Gaetano no formaron parte de la decoración de la capilla mayor, sino del retablorelicario dedicado a San Jacinto, que se sitúa junto al coro a los pies de la iglesia, donde fueron a parar gran parte del aparato taumatúrgico y de concitación del favor divino en este convento, del que como hemos comprobado también participaron los duques. En su interior se dispone únicamente el retablito que enmarcaba los dos óleos desaparecidos del Ecce Homo y la Virgen de la Piedad del Gaetano. Pero además, Madre de Dios contó con otro lienzo de Pulzone, hoy en una colección privada cordobesa ${ }^{19}$.

Del mismo modo, otras obras de alto valor en su tasación y procedentes de tierras italianas formaron parte de la manda testamentaria de doña Juana a la capilla que le sirvió de panteón. Entre ellos, los "treinta cuadros de ermitaños en lámina con su moldura de ébano, 6.100 reales", o los "diez y seis cuadros de la niñez de Cristo en lámina de guarnición de ébano, 6.400 reales" ${ }^{20}$. Los cuadros de ermitaños $(\approx 180 \times 230 \mathrm{~mm})$ se tratan de imágenes realizadas sobre lámina de cobre con la técnica del óleo que representan la única serie completa documentada hasta el momento en España de Solitudo sive Vitae Patrum Eremicolarum, compuesta de otras tantas planchas abiertas por los buriles de los hermanos Raphael y Johan Sadeler, siguiendo las composiciones de Marten de $\operatorname{Vos}^{21}$ [fig. 4].

De igual modo, los dieciséis cuadros de la niñez de Cristo (óleo sobre cobre, $\approx 470 \times 360 \mathrm{~mm}$ ), se basan en las doce planchas abiertas por Johan Sadeler para la serie de La Infancia de Jesús, a las que se unen otras cuatro de los buriles de Hieronimus Wierix de su Evangelicae Historiae imagines, todas ellas siguiendo composiciones de Vos [fig. 5].

También proceden del oratorio madrileño de doña Juana y se exponen en la capilla mayor conventual: (sic) "otro quadro de nuestra señora pequeño con san Joseph y el niño hechado con su marco dorado y negro", "un quadro de un niño jesus arrimado a la cruz con su marco, 33 rs.",

19 En 1995, Ruiz Manero señaló que la fotografía localizada en el Instituto Ametller de Barcelona de una pintura del convento Madre de Dios de Baena que representa la Sagrada Familia pudiera tratarse de una obra "posiblemente italiana y cercana en el tiempo al original", copia de la obra de Scipione Pulzone conservada en la Galería Borghese de Roma. Efectivamente, la "Santa Familia con San Juan y Santa Isabel, de tamaño natural y figuras enteras" que Ramírez de Arellano vio en el coro conventual a comienzos del siglo XX, es la Sagrada Familia que el Gaetano firmó y dató. Desconocemos cuáles fueron la vía de entrada en el convento, presumiblemente como regalo de profesión a alguna destacada religiosa. Fue dada a conocer por Moreno Cuadro en 1997 y formando parte en 2004 de una exposición en cuya ficha de catálogo no se hace referencia a su procedencia. Ruiz, 1995. Ramírez, 1983: 577. Moreno, 1997. Moreno, 2004: 242-245.

20 Barrio, 1984: 50.

${ }^{21}$ La referencia expresa de su compra en Roma: "135 moneta pagati di suo ordine a Bartolome Piselli pittore disse per prezzo di 30 quadretti delli Santi Padri dipinti in rame”. Libro de despachos, Roma, 18/12/1592. AHNOB, Baena, C. 12, D. 5, f. 35v. De Piselli sabemos que entre 1589 y 1591 perteneció a la 'Società' di San Luca, posterior Academia. Salvagni, 2008: 84-85. Si bien, el no aparecer en los elencos subsiguientes pudiera deberse a su consideración de pintor y bottegaio, excediendo así las exigencias que en 1593 se establecieron en los estatutos de la romana Academia de San Lucas. Cavazzini, 2011. 

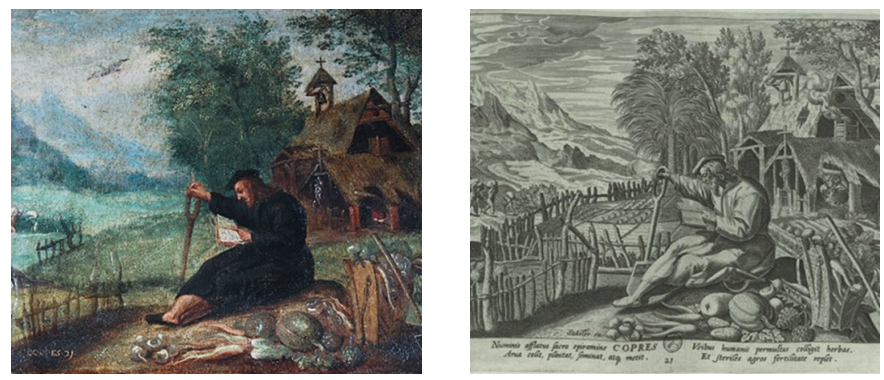

Fig. 4. Baena, iglesia conventual de Madre de Dios, capilla mayor, San Copres, ca. 1592 y el grabado de donde se inspira de la serie Solitudo sive Vitae Patrum Eremicolarum (ca. 1585), grabado de Johan Sadeler según Marten de Vos. Foto del autor.

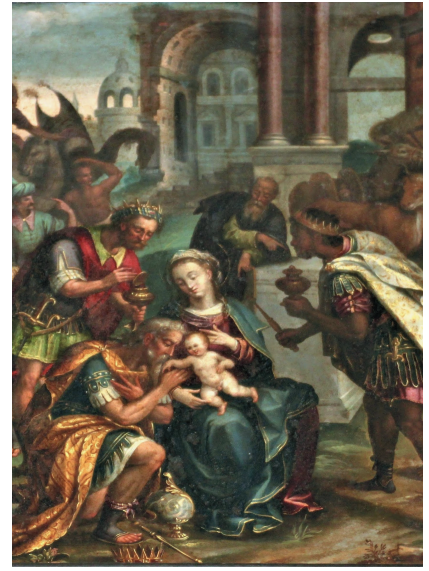

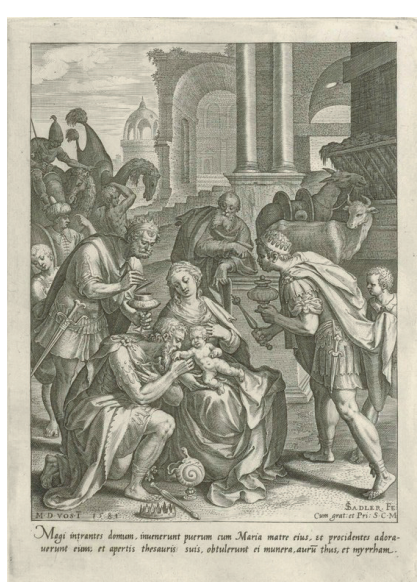

Fig. 5. Baena, iglesia conventual de Madre de Dios, capilla mayor, Adoración de los Reyes, autor anónimo, fines del siglo XVI y grabado de la serie La Infancia de Jesús, de Johan Sadeler según Marten de Vos. Foto del autor.

"otro quadro de otro niño Jesus con su túnica morada arrimado a la cruz, 33 rs." o "una ymagen de nuestra señora del populo con marco de ebano, 100 rs." 22 [fig. 6].

Además, visten este retablo pictórico otras obras, pero la falta de constatación documental tan solo nos permite señalar la posibilidad de que se traten de incorporaciones a la capilla mayor en los años posteriores al regreso del matrimonio ducal de su legación romana, pues, durante esos años se estaba abonando el terreno para la compra-apropiación del patronato. A todo ello ayudan las fuentes primarias, al habernos declarado en su momento la madre priora que en el revés de algunos cuadros se lee la inscripción "Regalo de nuestra señora la duquesa". Una vía de acceso por la que además podían haber recalado en Madre de Dios dos buenas composiciones de San José con el Niño Jesús y Santa Ana con la Virgen Niña, atribuibles a la escuela madrileña de comienzos del siglo XVII; como también las de indudable factura bassanesca de la Adoración de los Magos y Adoración de los Pastores ${ }^{23}$.

\section{A modo de conclusión abierta}

Creemos haber logrado contextualizar la importante dotación pictórica que realizaron al convento los $\mathrm{V}$ duques de Sessa desde que llegaron a Roma en legación diplomática, y con qué cantidad y calidad culminó el proyecto años después la duquesa doña Juana, quien hizo diferentes legados de reliquias, cuadros, ornamentos y la plata de su capilla particular madrileña para adorno de Madre de Dios de Baena. En ella lucen los lienzos procedentes del mercado madrileño junto a las piezas traídas de Italia. Todo lo cual nos habla de la importancia patrimonial que hoy continúa atesorando este convento de contemplativas dominicas cordobés.

\footnotetext{
22 Barrio, 1984: 50.

${ }^{23}$ Ruiz, 2011: 366.
} 


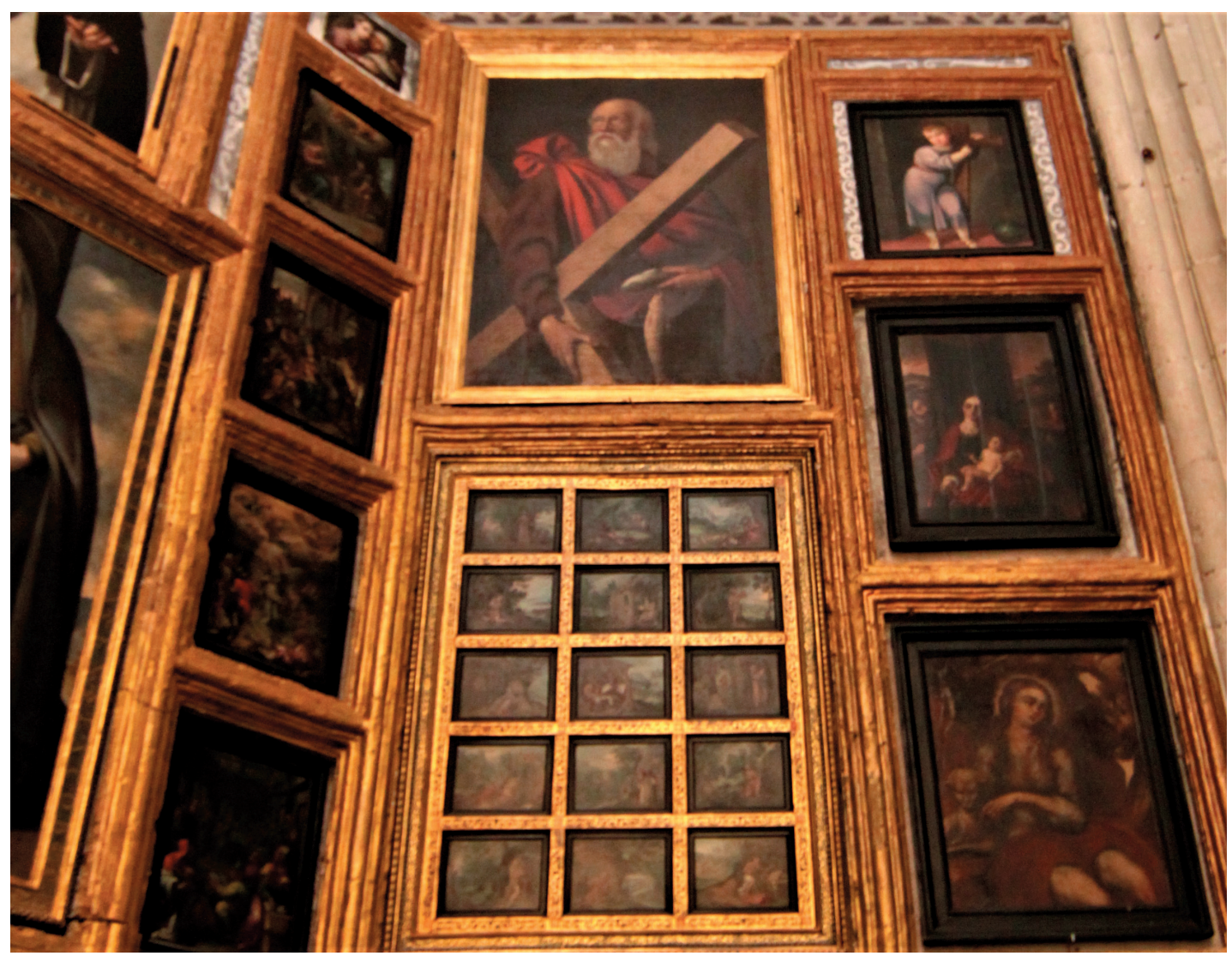

Fig. 6. Baena, iglesia conventual de Madre de Dios, detalle de la capilla mayor, donde se localizan distintas obras procedentes de la manda testamentaria realizada por la V duquesa de Sessa. Foto del autor.

De otro lado, concluimos este aporte con la innegable satisfacción de contribuir a engrosar el catálogo pictórico de Juan de Jáuregui con el San Andrés de Madre de Dios, del que una pertinente investigación técnico-artística podría servir para aproximarse a determinar otras posibles piezas realizadas de mano de este poeta-pintor.

\section{BIBLIOGRAFÍA}

Barrio, José L. (1983): “Bartolomé Román tasa dos cuadros de Scipione Pulzone y otro de Juan de Jáuregui”. En: Archivo Español de Arte, 224. Madrid, pp. 407-408.

Barrio, José L. (1984): “La librería y otros bienes de la duquesa de Sessa (1638)”. En: Cuadernos de Bibliofilia, 12. Valencia, pp. 41-51.

Carmona, Francisco M. (2017a): "El frustrado proyecto para panteón y sepulcro del duque de Sessa en Baena". En: Archivo Español de Arte, 357. Madrid, pp. 19-30.

Carmona, Francisco M. (2017b): “Obra y proyectos del gran cantero Luis González Bailén”. En: Anales de Historia del Arte, 27. Madrid, pp. 83-112.

Carmona, Francisco M. (2019a): "Parámetros nobiliarios y política de prestigio en el convento Madre de Dios de Baena (Córdoba)”. En: Hispania Sacra, 143. Madrid, pp. 191-208.

Carmona, Francisco M. (2019b): "Huella y presencia flamenca e italiana en los conventos cordobeses de Madres Dominicas”. En: Quintana, 18. Santiago de Compostela, pp. 147-166.

Cavazzini, Patrizia (2011): "Pittori eletti e 'bottegari' nei primi anni dell'Accademia e Compagnia di San Luca". En: Rivista d'arte, 1. Florencia, pp. 79-96.

Lafuente, Enrique (1948): La novela ejemplar de los retratos de Cervantes. Madrid: Dossat.

Lucía, José M. (2016): "Los retratos de Miguel de Cervantes: de la búsqueda del hombre al triunfo del mito". En: Imago. Revista de Emblemática y Cultura Visual, 8. Valencia, pp. 19-35. 
Monterroso, Antonio / García, Jorge (2010): El Palacio de España en Roma. Coleccionismo y antigüedades. Madrid: CSIC.

Moreno, Fernando (1997): "Nuevas pinturas italianas en Córdoba”. En: Perspectivas sobre Cultura Hispánica. Córdoba, Universidad, pp. 281-283.

Moreno, Fernando (comis.) (2004): Gratia Plena. La llena de Gracia; catálogo de exposición. Córdoba: CajaSur.

Ortiz, Dionisio / Bernier, Juan / Nieto, Manuel / Lara, Francisco (1981): Catálogo Artístico y Monumental de la provincia de Córdoba. Córdoba: Diputación, t.1.

Ramírez, Rafael (1983): Inventario monumental y artístico de la provincia de Córdoba. Córdoba: Diputación.

Ruiz, José M. (1995): “Obras y noticias de Girolamo Muziano, Marcello Venusti y Scipione Pulzone en España”. En: Archivo Español de Arte, 272. Madrid, pp. 365-380.

Ruiz, José M. (2011): Los Bassano en España. Madrid: FUE.

Salvagni, Isabella (2008): “Tra 'Società' e 'Academia' di San Luca: gli elenchi di «Pittori et alii» (1593-1608)". En: Fratarcangeli, M. (coord.), Intorno a Caravaggio. Dalla formazione alla fortuna. Roma, pp. 83-124.

Valverde, Francisco (1903): Historia de la villa de Baena. Toledo.

Fecha de recepción: 24-VI-2019

Fecha de aceptación: 26-XI-2019 